\title{
Comparisons of Ion Balance, Fruit Yield, Water, and Fertilizer Use Efficiencies in Open and Closed Soilless Culture of Paprika (Capsicum annuum L.)
}

\author{
Myat Thaint Ko ${ }^{1,2}$, Tae In Ahn ${ }^{1,2}$, and Jung Eek Son ${ }^{1,2 *}$ \\ ${ }^{1}$ Department of Plant Science, Seoul National University, Seoul 151-921, Korea \\ ${ }^{2}$ Research Institute for Agriculture \& Life Sciences, Seoul National University, Seoul 151-921, Korea
}

\begin{abstract}
Although closed soilless culture is useful for saving water and fertilizers with minimizing environmental pollution, adequate management of nutrient solutions is still not stabilized in greenhouse cultivation. In order to investigate the problems occurred in closed soilless culture of Paprika (Capsicum annuum L., cv. Fiesta), we compared ion balance, fruit yield, and the water and fertilizer use efficiencies in the closed system with those in the open system. The plants were grown in rockwool culture with a nutrient solution of EC 2.5 $\mathrm{dS} \cdot \mathrm{m}^{-1}$. After 4 weeks of treatment, individual ratio of $\mathrm{NO}_{3}^{-}, \mathrm{K}^{+}, \mathrm{Ca}^{2+}$, and $\mathrm{Mg}^{2+}$ to total ion concentrations $\left(\mathrm{meq} \cdot \mathrm{L}^{-1}\right)$ decreased from the initial value, especially the biggest decrement was observed in $\mathrm{K}^{+}$, and on the other hand, $\mathrm{SO}_{4}{ }^{2-}, \mathrm{Cl}^{-}$, and $\mathrm{Na}^{+}$were accumulated in the closed system. Yields after four-time harvests were $19 \%$ higher in the open system than in the closed system. Total volume of water used per unit area $\left(\mathrm{m}^{2}\right)$ in the open system was $20 \%$ higher, but the total water use per fruit was not significantly different between the two systems, while $t$ total fertilizer use per fruit was $78 \%$ higher in the closed system. Amount of marketable fruits was not significantly different between the two systems. We concluded that the increase in $\mathrm{K}^{+}$supply and the replenishment of recycled nutrient solution every four weeks were required for preventing the imbalance or depletion of nutrients in the close soilless culture of paprika plants to get more balanced nutrient composition during whole cultivation period.
\end{abstract}

Additional key words: ratio of nutrient composition, recycled soilless culture, reused nutrient solution

\section{Introduction}

In soilless culture, nutrient solution is managed in an openor closed-loop system. In the open system, the drainage solution containing considerable amount of nutrients causes soil and ground water pollution, while the closed soilless culture may overcome this problem by reusing water and nutrientswith improving water and nutrient use efficiencies (Giuffrida and Leonardi, 2011). However, recycling of drainage leads to imbalance of nutrient solution, resulting in the change of nutrient ratios (Savvas and Gizas, 2002).

As a reason for nutrient imbalance, it is reported that each nutrient is absorbed by plants though different mechanisms resulting variations in uptake efficiency (Sonneveld, 2000). Moreover, water and nutrient uptake are influenced by growth stage, climatic conditions (Noh et al., 2011; Sonneveld and van den Bos, 1995) and other environmental variables during the growing period. Therefore, water and nutrients should be adequately supplied considering the demand of plants in order to avoid an accumulation or depletion of nutrients in the closed system. To solve this problem, total nutrient strength and individual nutrient concentration in the recycled solution should be adjusted by using water and stock solutions. Estimation of daily replenishment needs by using indirect measurements of nutrient availability is an optional strategy (Weerakkody et al., 2007).

In general, the management of nutrient solution based on electrical conductivity has a difficulty in adjusting the ratio of individual ion concentration. For efficient management of nutrient solution, Savvas and Gizas (2002) tried to adjust individual ion ratio by chemical analysis every two weeks. Some reports indicated that the recirculation of nutrient solution had no effect on harvested parameters during the first 8 weeks but had a negative impact in average over the

\footnotetext{
*Corresponding author: sjeenv@snu.ac.kr

※ Received 25 February 2013; Revised 20 May 2013; Accepted 20 May 2013. This research was supported by iPET (Korea Institute of Planning and Evaluation for Technology of Food, Agriculture, Forestry and Fisheries) and KGSP (Korean Government Scholarship Program).
} 
entire harvest (Ehret et al., 2005; Hao and Papadopoulos, 2002; Raviv and Blom, 2001). Since adjustment frequency of recycled nutrient solutions based on chemical analysis is related to stability and operational cost in closed soilless culture, determination of an appropriate analysis period is important in commercialized farms.

The aims of this study was to investigate the changes in ion concentrations, its effect on fruit yield, and the water and fertilizer use efficiencies in closed soilless culture of paprika plants by comparing with those in the open system.

\section{Materials and Methods}

\section{Plant Materials and Experimental Conditions}

Paprika seedlings (Capsicum annuum L. cv. Fiesta) were transferred to rockwool cubes $(10 \mathrm{~cm} \times 10 \mathrm{~cm} \times 6.5 \mathrm{~cm})$. After two months, the plants were transplanted to the rockwool slabs $(90 \mathrm{~cm} \times 15 \mathrm{~cm} \times 7 \mathrm{~cm})$ with a density of 3 plants $/ \mathrm{m}^{2}$. The experiment was conducted in a venlo-type glasshouse at the experimental farm of Seoul National University (Suwon, Korea, Latitude $37.3^{\circ} \mathrm{N}$, Longitude $127.0^{\circ} \mathrm{E}$ ) from 39 days after transplanting (from end of June to end of August 2011). Environmental conditions during the growing period were shown in Fig. 1. Three slabs were installed for each system and placed in each gutter. In the closed system, a $20 \mathrm{~L}$ reservoir tank containing nutrient solution was used. The nutrient solution for supply was prepared in a mixing tank using two stock solutions adjusting desired $\mathrm{EC}$ and $\mathrm{pH}$ at $2.5 \mathrm{dS} \cdot \mathrm{m}^{-1}$ and 5.5 to 6.5 , respectively. Compositions of fresh nutrient solution $\left(\mathrm{meq} \cdot \mathrm{L}^{-1}\right)$ were $14.17 \mathrm{NO}_{3}^{-}, 1.14 \mathrm{H}_{2} \mathrm{PO}_{4}^{-}, 5.92$ $\mathrm{K}^{+}, 8.85 \mathrm{Ca}^{2+}, 3.17 \mathrm{Mg}^{2+}$ and $3.2 \mathrm{SO}_{4}^{2-}$. A pump connected to drip emitters (flow rate of $35 \mathrm{~mL} \cdot \mathrm{min}^{-1}$ ) controlled by a timer was used for irrigation. Drainage ratio was maintained within 20 to $50 \%$ at each irrigation event. Nutrient solution was supplied four times per day $(7: 00,10: 00,14: 00$, and

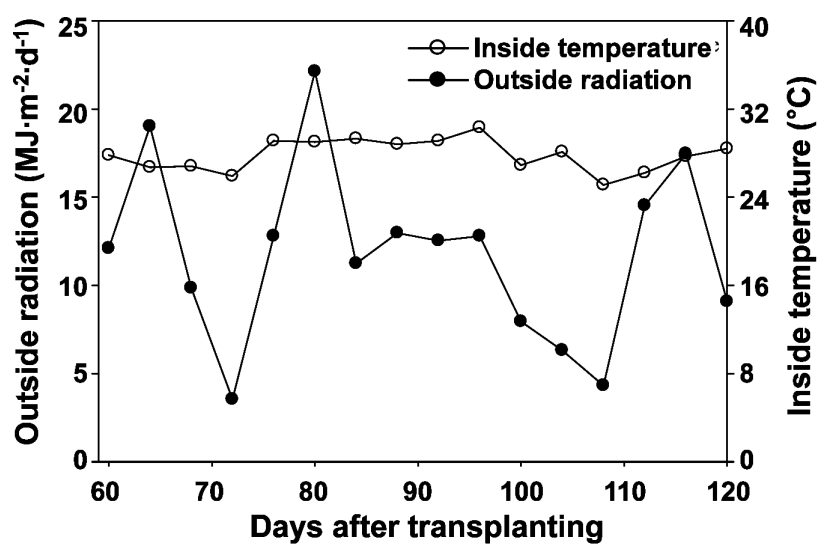

Fig. 1. Changes in indoor temperature and solar radiation during the treatment period.
16:00) for 5 to $10 \mathrm{~min}$ each. The plants were pruned to form two main stems, which were vertically trellised to a "V" canopy system (Jovicich et al., 2004) and the additional plant management of pruning and training were carried out every week.

\section{Measurements}

The entire quantity of drainage directly returned to the recycled tank. The $\mathrm{EC}, \mathrm{pH}$, and volume of recycled nutrient solution in the tanks of the closed system were measured every three days and the tanks were refilled with water and fresh nutrient solution until EC of the solution reaching 2.5 $\mathrm{dS} \cdot \mathrm{m}^{-1}$. The volume of nutrient solution in the tank was kept constant every three day. The $\mathrm{EC}$ and $\mathrm{pH}$ of recycled nutrient solution were measured by using a conductivity meter (D-54, Model-352734-1, Horiba, Japan). Every two weeks, nutrient solutions from all the recycled tanks were sampled and analyzed: $\mathrm{NO}_{3}^{-}, \mathrm{H}_{2} \mathrm{PO}_{4}^{-}, \mathrm{Cl}^{-}$, and $\mathrm{SO}_{4}{ }^{2-}$ by an Ion Chromatography (ICS-3000, Dionex, Sunnyvale, CA, USA) and $\mathrm{K}^{+}, \mathrm{Ca}^{2+}, \mathrm{Mg}^{2+}$, and $\mathrm{Na}^{+}$by an Inductively Coupled Plasma-Atomic Emission Spectrometry (ICP-730 ES, Varian, Inc, USA). At each harvest, fruit number, fruit fresh and dry weights were measured. Fruits were dried in a thermo-ventilated oven at $65^{\circ} \mathrm{C}$ until reaching a constant weight. Fruits were divided into marketable and not marketable (fruits with cracks on the epicarp or small size and miss-shaped) and blossom end rot. Harvesting started onmid-July and ended at the end of August.

\section{Water and Fertilizer Use Efficiencies}

In the closed system, the reduced volume of nutrient solution inside the recycled tank and the added volumes of water and nutrient solution were measured. Total volume of water used was calculated using the total volume of water supplied to the plants. The following formula was used to calculate the water and fertilizer use efficiencies (Jovicich et al., 2007).

Total used water per fruit $\left(\mathrm{L} \cdot \mathrm{kg}^{-1}\right)$

$=$ Total water delivered $\left(\mathrm{L} \cdot \mathrm{m}^{-2}\right) /$ fruit yield $\left(\mathrm{kg} \cdot \mathrm{m}^{-2}\right)$

Total used fertilizers per fruit $\left(\mathrm{g} \cdot \mathrm{kg}^{-1}\right.$ fruit $)$

$=$ Total fertilizers used $\left(\mathrm{g} \cdot \mathrm{m}^{-2}\right) /$ fruit yield $\left(\mathrm{kg} \cdot \mathrm{m}^{-2}\right)$

\section{Statistical Analysis}

The two systems with three replications (slabs) were compared with the time and three plants were grown in each slab. Data were subjected to single factor analyses of variance using SAS 9.2 (SAS Institute, Cary, NC, USA) and means were separated by Duncan's multiple range tests at $(P=$ 
0.05). Treatment means of ion concentration changes in the open and closed systems were performed using SigmaPlot 10.0 (Systat Software, Inc, San Jose, CA, USA).

\section{Results and Discussion}

\section{$\mathrm{EC}$ and $\mathrm{pH}$ in the Recycled Nutrient Solution}

The EC in recycled nutrient solution significantly increased from the initial set value of $2.5 \mathrm{dS} \cdot \mathrm{m}^{-1}$ for 14 to 42 days after treatment and then decreased (Fig. 2A). It might be due to the uptake of more water than nutrients by plants during 14 to 42 days. In fact, the depleted volume was supplemented with water and fresh nutrient solution for adjusting EC and constant volume three times a week. The changes in the EC and composition of recycled nutrient solution were supposed to from the imbalance in uptake ratio of water and nutrient. Lopez et al. (2003) reported that when the nutrient solution is recycled, sulfate, bicarbonate and chloride ions may accumulate resulting in a significant increase
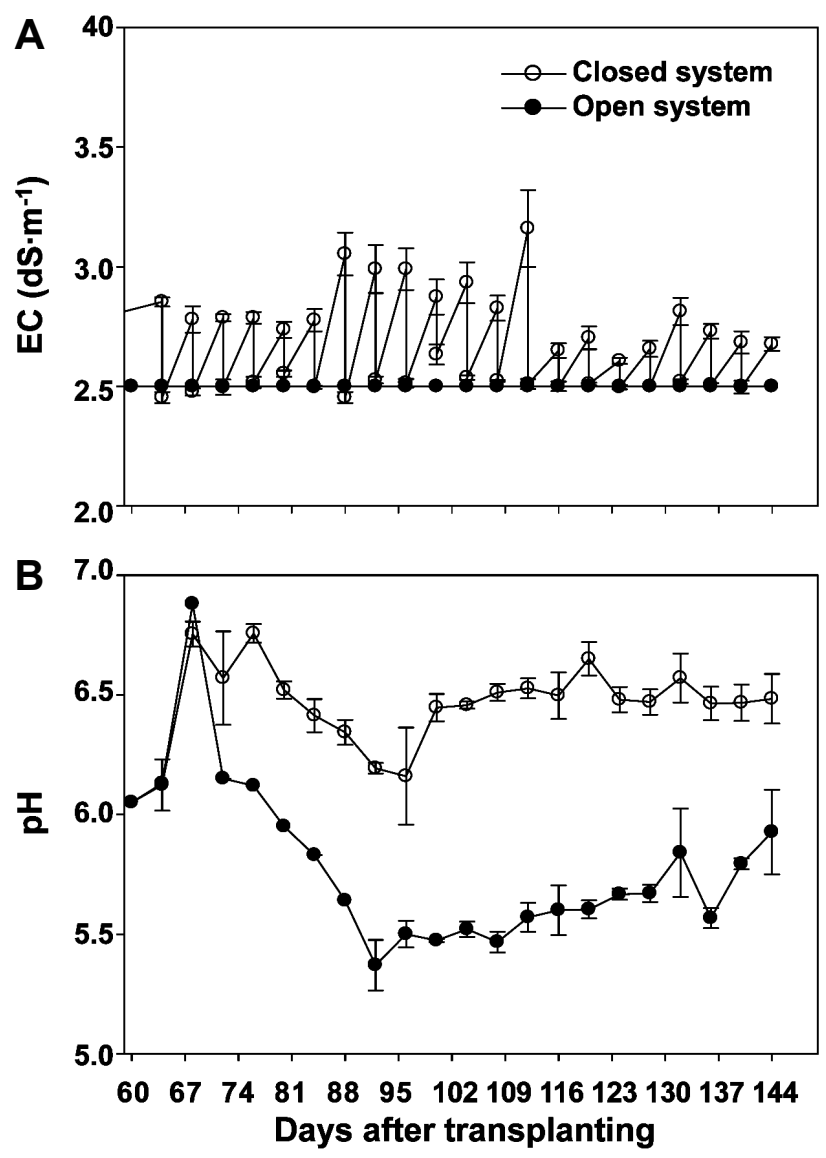

Fig. 2. Change in the EC of recycled nutrient solution in the closed system (A). Periodical decline of EC is due to adding of fresh nutrient solution and water for adjusting EC. Dash-line means $\mathrm{EC}$ in the open system. Changes in the $\mathrm{pH}$ of drainage in the open system and that of recycled nutrient solution of the closed system $(B)$. Vertical bars indicate \pm SE of the mean $(n=3)$. of EC. Although the $\mathrm{pH}$ of drainage solution in the closed system was observed within 5.5 to 6.5 , it was a little higher than that in the open system (Fig. 2B). It might be caused due to more anion uptake in the closed system as reported by Savvas and Gizas (2002).

\section{Nutrient Composition in the Recycled Nutrient Solution}

No significant change in ion ratio was observed in cation (Fig. 3), while a significant change was observed in anion in the recycled nutrient solution (Fig. 4). In fact, nutrient and non-nutrient concentration may largely influence on nutrient and water uptake kinetics (Le Bot et al., 1998; Parida and Das, 2005). After 4 weeks of treatment, individual ratio of

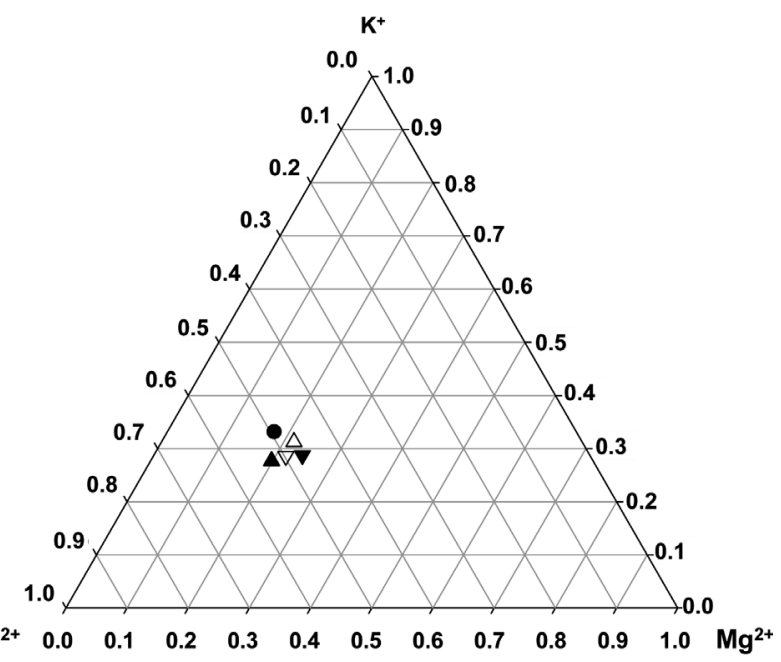

Fig. 3. Change in cation ratio of individual ion concentration (meq $\cdot \mathrm{L}^{-1}$ ) of recycled nutrient solution with time in the closed soilless culture system ( initial, $\triangle$ week 2 , $\Delta$ week $4, \nabla$ week 6 , and $\nabla$ week 8) under a constant EC of $2.5 \mathrm{dS} \cdot \mathrm{m}^{-1}$.

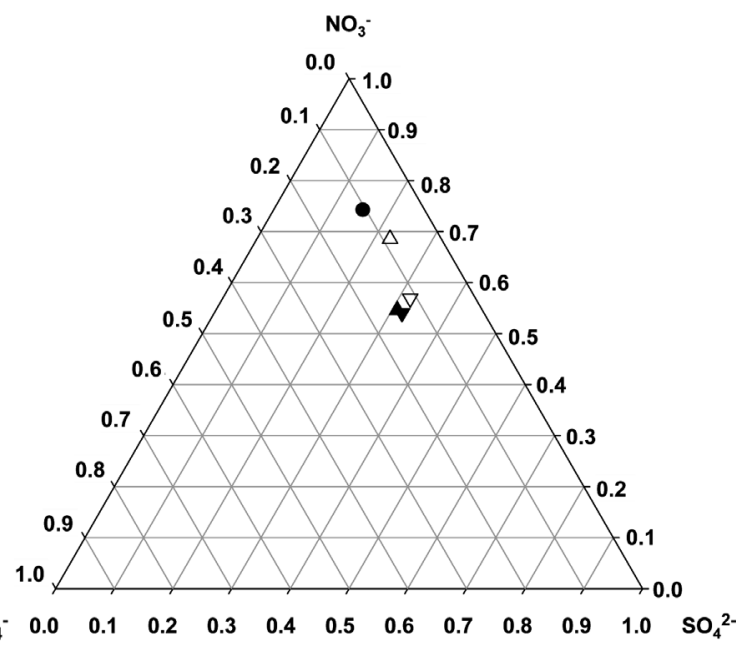

Fig. 4. Change in anion ratio of individual ion concentration (meq $\cdot \mathrm{L}^{-1}$ ) of recycled nutrient solution with time in the closed soilless culture system ( initial, $\triangle$ week $2, \Delta$ week $4, \nabla$ week 6 , and $\boldsymbol{\nabla}$ week 8) under a constant EC of $2.5 \mathrm{dS} \cdot \mathrm{m}^{-1}$. 
$\mathrm{NO}_{3}^{-}, \mathrm{K}^{+}, \mathrm{Ca}^{2+}$, and $\mathrm{Mg}^{2+}$ to total ion concentration (meq $\cdot \mathrm{L}^{-1}$ ) in the recycled nutrient solution decreased from the initial value, especially the biggest decrement was observed in $\mathrm{K}^{+}$ (Fig. 5). For a reason, Marcussi et al. (2004) reported that $\mathrm{NO}_{3}{ }^{-}$and $\mathrm{K}^{+}$were the most required macro nutrients in sweet peppers, followed by $\mathrm{Ca}^{2+}, \mathrm{Mg}^{2+}, \mathrm{SO}_{4}{ }^{2-}$, and $\mathrm{PO}_{4}{ }^{3-}$ in the decreasing order. Climate and growth variables during the entire cultivation cycle were also related to nutrient absorption patterns (Silberbush and Lieth, 2004). Meanwhile, accumulation of $\mathrm{SO}_{4}{ }^{2-}$ as well as a progressive increase in $\mathrm{Cl}^{-}$and $\mathrm{Na}^{+}$ were observed in the closed system (Figs. 5 and 6). This condition is generally found in recycled nutrient solution due to relatively poor absorption of those ions by plants (Savvas and Gizas, 2002). Although the set EC value of $2.5 \mathrm{dS} \cdot \mathrm{cm}^{-1}$ was controlled by adding water and fresh nutrient solution, sum of each cation $\left(\mathrm{K}^{+}, \mathrm{Ca}^{2+}, \mathrm{Mg}^{2+}\right.$, and $\left.\mathrm{Na}^{+}\right)$and anion $\left(\mathrm{NO}_{3}^{-}, \mathrm{H}_{2} \mathrm{PO}_{4}^{-}, \mathrm{SO}_{4}^{2-}\right.$, and $\left.\mathrm{Cl}^{-}\right)$concentration $\left(\mathrm{meq} \cdot \mathrm{L}^{-1}\right)$ in the recycled nutrient solution increased rather than the initial value (Fig. 7). It might be due to the significant reductions in $\mathrm{NO}_{3}^{-}, \mathrm{K}^{+}, \mathrm{Ca}^{2+}$, and $\mathrm{Mg}^{2+}$ and the accumulation of $\mathrm{SO}_{4}{ }^{2-}$,

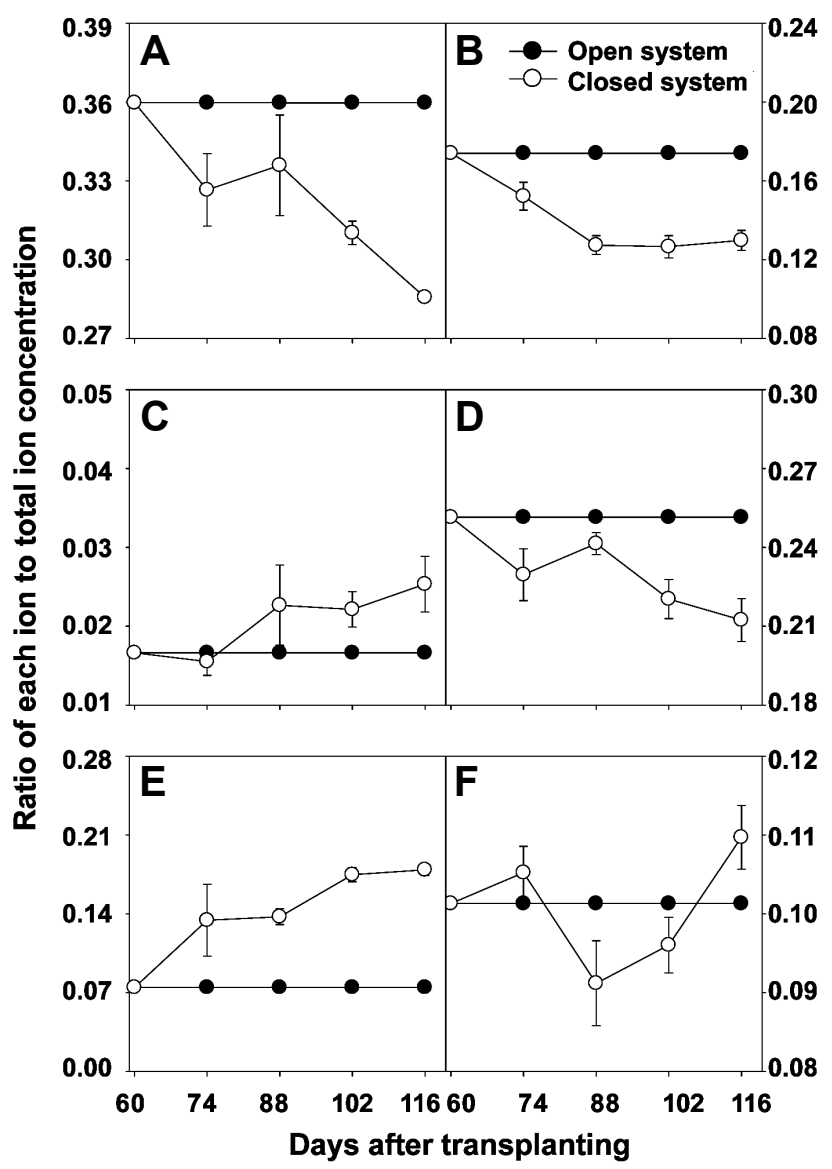

Fig. 5. Change in ratio of individual ion concentration to the total ion concentrations $\left(\mathrm{meq} \cdot \mathrm{L}^{-1}\right)$ in the recycled nutrient solution of closed soilless culture system. In the open system, ion concentration was the same as the initial value. Vertical bar indicate \pm SE of the mean $(n=3)$.
$\mathrm{Cl}^{-}$, and $\mathrm{Na}^{+}$as shown in Figs. 5 and 6. Ionic contributions of $\mathrm{NO}_{3}{ }^{-}$and $\mathrm{K}^{+}$to $\mathrm{EC}$ reading were the greatest and followed by $\mathrm{Ca}^{2+}, \mathrm{SO}_{4}{ }^{2-}$, and $\mathrm{Mg}^{2+}$ in the order (Ahn and Son, 2011). On the other hand, ion uptakes became lower than expected and led to ion accumulation in the closed system. This tendency was more pronounced by anion accumulation 4 weeks after treatment. Therefore, frequent nutrient replenishments should be required every 4 weeks to maintain constant ion ratio in the closed system.

\section{Fruit Yield}

Total number of fruits and yields per $\mathrm{m}^{2}$ were $22 \%$ and $19 \%$ less in the closed system than the open system, respectively (Table 1). Fruit weight was relatively higher in the closed system. Since adjustment of the reused nutrient solution in the closed system was based on $\mathrm{pH}$ and EC instead of instantaneous renewal or mineral analysis, nutrient imbalance

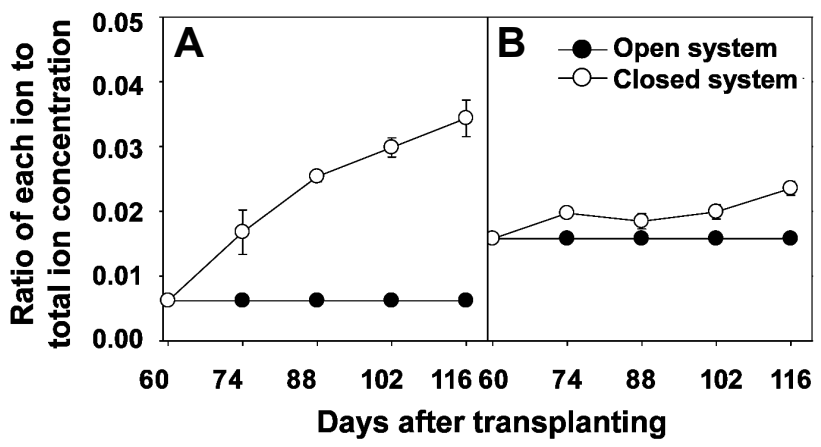

Fig. 6. Change in ratio of $\mathrm{Cl}^{-}$or $\mathrm{Na}^{+}$concentration to the total ion concentrations (meq $\cdot \mathrm{L}^{-1}$ ) in the recycled nutrient solution of closed soilless culture system. In the open system, ion concentration was the same as the initial value. Vertical bar indicate \pm SE of the mean $(n=3)$.

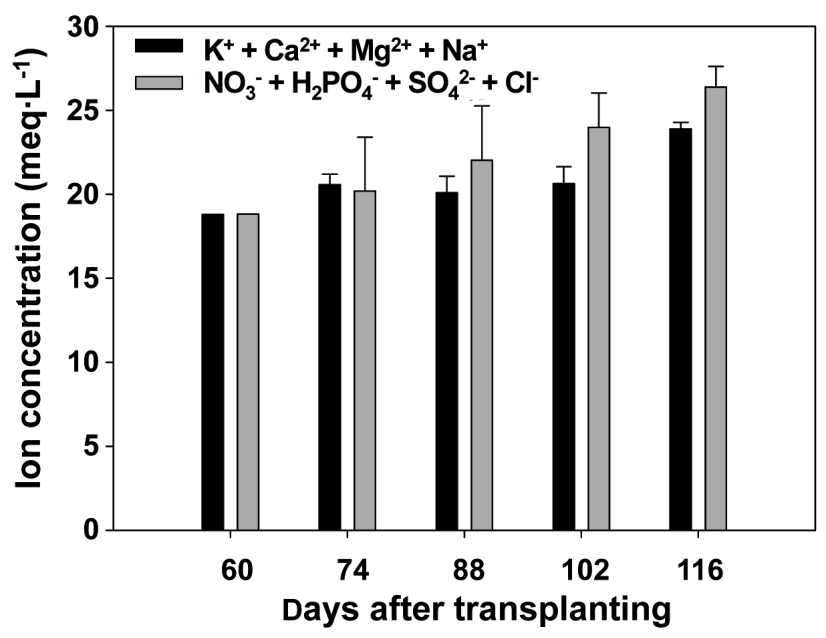

Fig. 7. Change in sum of $(\square)$ cation $\left(\mathrm{K}^{+}+\mathrm{Ca}^{2+}+\mathrm{Mg}^{2+}+\mathrm{Na}^{+}\right)$ and $(\square)$ anion $\left(\mathrm{NO}_{3}^{-}+\mathrm{H}_{2} \mathrm{PO}_{4}^{-}+\mathrm{SO}_{4}{ }^{2-}+\mathrm{Cl}^{-}\right)$concentrations in the recycled nutrient solution after adjusting $\mathrm{EC}$ by adding water and fresh nutrient solution. Vertical bar indicate \pm SE of the mean $(n=3)$. 
in the solution was expected to affect both crop yield and quality. When the drainage solution was reused, the highest yield was obtained with the supply of highest ratio of $\mathrm{K}^{+}$: $\left(\mathrm{K}^{+}+\mathrm{Ca}^{2+}+\mathrm{Mg}^{2+}\right)$ than those recommended in open system (Savvas and Gizas, 2002). This seems to be true that the decrease of $\mathrm{K}^{+}:\left(\mathrm{K}^{+}+\mathrm{Ca}^{2+}+\mathrm{Mg}^{2+}\right)$ ratio in the reused nutrient solution with time Fig. 3 and resulted $19 \%$ yield reduction was observed in this study. The accumulation of $\mathrm{SO}_{4}{ }^{2-}$ in the recycled nutrient solution is a common phenomenon in the closed soilless culture, which has been implicated to restrict the yield of tomatoes grown in NFT (Lopez et al., 1996; Zekki et al., 1996).

\section{Total Used Water and Fertilizers per Fruit}

Total water and fertilizers used per fruit in the open and closed systems were given in Table 2 . Total volume of water used in the open system was $44.1 \mathrm{~L} \cdot \mathrm{m}^{-2}$ while that in the closed system was $35.5 \mathrm{~L} \cdot \mathrm{m}^{-2}$ with a $20 \%$ saving of nutrient solution. Total volume of water delivered per $\mathrm{kg}$ of fruit was $5 \%$ less in the closed system $\left(20.1 \mathrm{~L} \cdot \mathrm{kg}^{-1}\right)$ than the open system $\left(21.1 \mathrm{~L} \cdot \mathrm{kg}^{-1}\right)$. Total fertilizer used $\left(42.5 \mathrm{~g} \cdot \mathrm{m}^{-2}\right)$ was $81 \%$ less in the closed system than the open system $\left(227.3 \mathrm{~g} \cdot \mathrm{m}^{-2}\right)$. As results, the average fertilizers used for per $\mathrm{kg}$ of fruit were $78 \%$ lower in the closed system than the open system. For improving the water and fertilizer use efficiencies, Giuffrida and Leonardi (2011) used lower nutrient concentration on peppers grown in closed soilless culture and Ta et al. (2012) applied the irrigation frequency to paprika plants efficiently.

In this study, we compared the nutrient balance, fruit yield, water and fertilizer use efficiencies in the open and closed soilless cultures of paprika plants. To optimize the nutrient status in the closed soilless culture of paprika plants, it is needed to increase $\mathrm{K}^{+}$supply and to replenish every four weeks for preventing the accumulation of $\mathrm{SO}_{4}{ }^{2-}$ in reused nutrient solution because the proportion of anion greatly increased 4 weeks after treatment. It is possible to increase the water and fertilizer use efficiencies without reduction of yield and quality by using adequate nutrient management in closed soilless culture.

\section{Literature Cited}

Ahn, T.I and J.E. Son. 2011. Changes in ion balance and individual ionic contributions to EC reading at different renewal intervals of nutrient solution under EC-based nutrient control in closedloop soilless culture for sweet peppers (Capsicum annuиm L. 'Fiesta'). Kor. J. Hort. Sci. Technol. 29:29-35.

Ehret, D., J. Menzies, and T. Helmer. 2005. Production and quality of greenhouse roses in recirculating nutrient systems. Sci. Hort. 106:103-113.

Giuffrida, F. and C. Leonardi. 2011. Nutrient solution concentration on pepper grown in a soilless closed system: Yield, fruit quality, water and nutrient efficiency. Acta Agr. Scand. B-Sp. $1-6$.

Hao, H. and A.P. Papadopoulous. 2004. Effects of calcium and magnesium on plant growth, biomass partitioning and fruit yield of winter greenhouse tomato. Hort. Sci. 39:512-515.

Jovicich, E., D.J. Cantliffe, and P.J. Stofella. 2004. Fruit yield and quality of greenhouse grown bell pepper as influenced by density,container and trellis system. HortTechnology 14: 507-513.

Jovicich, E., P.J. Stofella, and D.Z. Haman. 2007. Bell pepper fruit yield and quality as influenced by solar radiation-based irrigation and container media in a passively ventilated greenhouse. HortScience 42:642-652.

Le Bot, J., S. Adamowicz, and P. Robin. 1998. Modelling plant nutrition of horticultural crops: A review. Sci. Hort. 74:47-82.

Table 1. Growth and yield of paprika plants in the open and closed soilless culture systems.

\begin{tabular}{lccr}
\hline \hline & Open system & Closed system & \% Reduction in closed system \\
\hline Total number of fruits $/ \mathrm{m}^{2}$ & $18 \pm 4^{z}$ & $14 \pm 4$ & 22 \\
Yield/plant $(\mathrm{g})$ & $726.7 \pm 170.7$ & $590.4 \pm 37.6$ & 19 \\
Mean fruit wt. (g/fruit) & $102.5 \pm 7.9$ & $129.8 \pm 16.3$ & - \\
Number of marketable fruits $/ \mathrm{m}^{2}$ & $13 \pm 2$ & $10 \pm 3$ & - \\
\hline
\end{tabular}

${ }^{\mathrm{z}}$ Each value represents mean \pm SE $(n=9)$.

Table 2. Total used amounts of water and fertilizer in the open and closed soilless culture systems.

\begin{tabular}{lccc}
\hline \hline & Open system & Closed system & \% Reduction in closed system \\
\hline Total water used $\left(\mathrm{L} \cdot \mathrm{m}^{-2}\right)$ & 44.1 & $35.5 \pm 3.2^{\mathrm{z}}$ & 20 \\
Total fertilizer used $\left(\mathrm{g} \cdot \mathrm{m}^{-2}\right)$ & 227.3 & $42.5 \pm 1.7$ & 81 \\
Used water per fruit $\left(\mathrm{L} \cdot \mathrm{kg}^{-1}\right.$ fruit) & $21.1 \pm 5.7$ & $20.1 \pm 1.4$ & 5 \\
Used fertilizers per fruit $\left(\mathrm{g} \cdot \mathrm{kg}^{-1}\right.$ fruit) & $108.9 \pm 29.5$ & $24.0 \pm 0.9$ & 78 \\
\hline
\end{tabular}

${ }^{\mathrm{z}}$ Each value represents mean \pm SE $(n=3)$. In open system, the total amount of water and fertilizer used are the same in 3 replications. 
Lopez, J., J. Santos-Perez, and S. Lozano-Trejo. 2003. Mineral nutrition and productivity of hydroponically grown tomatoes in relation to nutrient solution recycling. Acta Hort. 609:219-223.

Lopez, J., N. Tremblay, W. Voogt, S. Dube, and A. Gosselin. 1996. Effects of varying sulphate concentrations on growth, physiology and yield of the greenhouse tomato. Sci. Hort. 67:207-217.

Marcussi, F.F.N., R.L. Villas Boas, L.J.G. Gody, and R. Goto. 2004. Macronutrient accumulation and portioning in fertigated sweet pepper plants. Sci. Agric. 61:62-68.

Noh, E.H., H.J. Jun, and J.E. Son. 2011. Growth characteristics and nutrient uptake of kalanchoe plants (Kalanchoe blossfeldiana 'Marlene') at different light intensities and nutrient strengths in ebb and flow subirrigation systems. Kor. J. Hort. Sci. Technol. 29:187-194.

Parida, A.K. and A.B. Das. 2005. Salt tolerance and salinity effects on plants: A review. Ecotox Environ Safe 60:324-349.

Raviv, M. and T.J. Blom. 2001. The effect of water availability and quality on photosynthesis and productivity of soilless-grown cut roses. Sci. Hort. 88:257-276.

Savvas, D. and G. Gizas. 2002. Response of hydroponically grown gerbera to nutrient solution recycling and different nutrient cation ratios. Sci. Hort. 96:267-280.
Silberbush, M., and J.H. Lieth. 2004. Nitrate and potassium uptake by greenhouse roses (Rosa hybrid) along successive flower-cut cycles: A model and its calibration. Sci. Hort. 101:127-141.

Sonneveld, C. 2000. Effect of salinity on substrate grown vegetables and ornamentas in greenhouse horticulture. $\mathrm{PhD}$ Thesis, Wageningen Agricultural University, Wageningen, The Netherlands.

Sonneveld, C. and A.L. van den Bos. 1995. Effects of nutrient levels on growth and quality of radish (Raphanus sativus L.) grown on different substrates. J. Plant Nutr. 18:501-513.

Ta, T.H., J.W. Shin, E.H. Noh, and J.E. Son. 2012. Transpiration, growth and water use efficiency of paprika plants (Capsicum anпuит L.) as affected by irrigation frequency. Hort. Environ. Biotechnol. 53:129-134.

Weerakkody, W.A.P., M.A.P. Mayakaduwa, and K.N. Weerapperuma. 2007. Effect of supply volume and weather based EC adjustments on the growth and yield of greenhouse tomato and bell pepper. Acta Hort. 742:105-111.

Zekki, H., L. Gauthier, and A. Gosselin. 1996. Growth, productivity and mineral composition of hydroponically cultivated greenhouse tomatoes, with or without nutrient solution recycling. J. Am. Soc. Hort. Sci. 121:1082-1088. 